\title{
A New Class of Lithium Ion Conductors with Tunable Structures and Compositions: Quaternary Diamond-like Thiogermanates
}

Jacilynn A. Brant, ${ }^{\dagger}$ Kasey P. Devlin, ${ }^{\dagger}$ Christian Bischoff, ${ }^{\dagger}$ Deborah Watson, ${ }^{\dagger}$ Steve W. Martin,,${ }^{\ddagger}$ Michael D. Gross, ${ }^{\bar{\top}}$ Jennifer A. Aitken ${ }^{\dagger, *}$

${ }^{\dagger}$ Department of Chemistry and Biochemistry, Duquesne University, Pittsburgh Pennsylvania 15282 USA

${ }^{ \pm}$Department of Materials Science and Engineering, Iowa State University, Ames Iowa 50011 USA

${ }^{\bar{T}}$ Department of Chemistry, Wake Forest University, Winston-Salem, North Carolina 27109, USA

* Department of Chemistry and Biochemistry, Duquesne University, 600 Forbes Ave, Pittsburgh Pennsylvania 15282 USA; (412) 396-1670; aitkenj@duq.edu 
ABSTRACT: The new $\mathrm{Li}_{2} \mathrm{CoGeS}_{4}$ compound crystallizes in the $P n$ space group with the wurtzkesterite structure, according to single crystal X-ray diffraction. The structure of $\mathrm{Li}_{2} \mathrm{CoGeS}_{4}$, and the high degree of phase-purity in which it is prepared, are supported by high-resolution synchrotron X-ray powder diffraction. Varying the divalent ion in $\mathrm{Li}_{2}-\mathrm{II}-\mathrm{GeS}_{4}$ materials yields three different structure types, all of which are derived from hexagonal diamond. These structural variations give rise to $\mathrm{Li}^{+}-$ encompassing [II-GeS $]_{4}^{2-}$ nets with different topologies that offer diversity in lithium ion diffusion pathways. In the first systematic study of the lithium ion conductivity in quaternary diamond-like materials, wurtz-kesterite-type $\mathrm{Li}_{2} \mathrm{CoGeS}_{4}$ and $\mathrm{Li}_{2} \mathrm{FeGeS}_{4}$ (Pn), lithium cobalt(II) silicate-type $\mathrm{Li}_{2} \mathrm{MnGeS}_{4}\left(P n a 2_{1}\right)$, and wurtz-stannite-type $\mathrm{Li}_{2} \mathrm{CdGeS}_{4}\left(P m n 2_{1}\right)$ are presented as environmentally stable lithium ion conductors. These materials are comprised of cubic diamond-like $\left[\mathrm{CoGeS}_{4}\right]^{2-}$ and $\left[\mathrm{FeGeS}_{4}\right]^{2-}$ anionic frameworks, $\mathrm{ABW}-$ like $\left[\mathrm{MnGeS}_{4}\right]^{2-}$, and square lattice-like $\left[\mathrm{CdGeS}_{4}\right]^{2-}$. As assessed using impedance spectroscopy, $\mathrm{Li}_{2} \mathrm{FeGeS}_{4}$ exhibits the most promising $\mathrm{Li}^{+}$ion conductivity of $1.8(3) \times 10^{-4} \mathrm{~S} / \mathrm{cm}$ at $100{ }^{\circ} \mathrm{C}$, while $\mathrm{Li}_{2} \mathrm{CdGeS}_{4}$ shows the lowest activation energy for lithium ion conduction, $\mathrm{E}_{\mathrm{A}}=0.74(2) \mathrm{eV}$.

KEYWORDS: LISICON, ion conductivity, thiogermanate, solid-state electrolyte, kesterite, stannite 


\subsection{INTRODUCTION}

Simple diamond-structured materials such as elemental silicon and gallium arsenide have found applications in surging technologies, e.g. integrated circuits and field-effect transistors, in the electronics industry. ${ }^{1}$ Ternary I-III- $\mathrm{VI}_{2}$ diamond-like materials, such as silver gallium sulfide, ${ }^{2}$ are widely used in infrared nonlinear optical devices. Quaternary diamond-like materials exhibit a higher degree of compositional flexibility, providing an attractive platform for physical property tuning for an array of potential applications. Many compounds in this family can be accessed with relatively simple structure types, from which composition-structure-property relationships can be elucidated to accelerate the design of multifunctional materials and those tailor-made for specific applications. Quaternary diamondlike materials with the general formula of $\mathrm{I}_{2}-\mathrm{II}-\mathrm{IV}-\mathrm{VI}_{4}$ are gaining increased attention for applications in photovoltaics, ${ }^{3}$ thermoelectrics, ${ }^{4}$ and nonlinear optics. ${ }^{5}$ Yet, the full potential for applications of $\mathrm{I}_{2}$-II-IV-VI $\mathrm{VI}_{4}$ chalcogenides remains to be realized and much of the compositional space has not yet been explored.

Here we demonstrate that lithium ions can be integrated into the family of $\mathrm{I}_{2}$-II-IV-VI $\mathrm{I}_{4}$ diamond-like materials to target new solid-state electrolytes. Solid-state lithium ion conductors are an important component in all-solid-state batteries, and hold promise for solving safety issues associated with current rechargeable batteries constructed from liquid electrolytes if critical parameters (e.g., lithium ion conductivity, stability) could be optimized. ${ }^{6}$ While oxides are readily investigated toward the discovery of solid-state electrolytes due to air-stability, ease of preparation and long shelf lives, they are afflicted by shortcomings. For example, lithium lanthanum titanate is one of the fastest solid-state lithium ion conductors $\left(1 \times 10^{-3} \mathrm{~S} / \mathrm{cm} \text { at } \mathrm{RT} \text { for } \mathrm{Li}_{3 \mathrm{x}} \mathrm{La}_{(2 / 3)-\mathrm{x}} \quad(1 / 3)-2 \mathrm{x} \mathrm{TiO}_{3} \text { when } \mathrm{x}=0.11\right)^{7}$, but a lack of control over the lithium content is a major drawback. Chalcogenides are capable of reaching higher ion conductivities $^{8}$ since the higher polarizability of larger chalcogenides, in comparison with $\mathrm{O}^{2-}$, leads to weakened interactions between the anion and the lithium cation that can better promote ion diffusion. ${ }^{8 \mathrm{~b}}$ Thus, lithium sulfides hold even greater prospect. ${ }^{9}$ Accordingly, much progress has been achieved in 
the investigation of lithium chalcogenides for solid-state electrolyte applications, such as lithium thiosilicates, ${ }^{9 f, 10}$ lithium thiogermanates, ${ }^{9 \mathrm{~d}, 11}$ and lithium thiostannates ${ }^{12}$ with room temperature ion conductivities up to $6.4 \times 10^{-4} \mathrm{~S} / \mathrm{cm}$ for $\mathrm{Li}_{3.4} \mathrm{Si}_{0.4} \mathrm{P}_{0.6} \mathrm{~S}_{4},{ }^{10} 2 \times 10^{-7} \mathrm{~S} / \mathrm{cm}$ for $\mathrm{Li}_{4} \mathrm{GeS}_{4}{ }^{11}$ and $7 \times 10^{-5} \mathrm{~S} / \mathrm{cm}$ for $\mathrm{Li}_{4} \mathrm{SnS}_{4}{ }^{12 \mathrm{a}}$ in ceramic pellets. Interestingly, according to ${ }^{7} \mathrm{Li}$ pulsed field gradient (PFG) NMR, $\mathrm{Li}_{11} \mathrm{SiP}_{2} \mathrm{~S}_{12}{ }^{9 \mathrm{f}}$ exhibits higher lithium ion diffusivity in comparison to $\mathrm{Li}_{10} \mathrm{GeP}_{2} \mathrm{~S}_{12}{ }^{9 \mathrm{~d}}$ for which the highest $\mathrm{Li}^{+}$ion conductivity of $1.2 \times 10^{-2} \mathrm{~S} / \mathrm{cm}$ at room temperature has been observed. However, $\mathrm{Li}_{11} \mathrm{SiP}_{2} \mathrm{~S}_{12}{ }^{9 \mathrm{f}}$ is plagued by synthesis scalability and phase-purity issues, while both $\mathrm{Li}_{11} \mathrm{SiP}_{2} \mathrm{~S}_{12}$ and $\mathrm{Li}_{10} \mathrm{GeP}_{2} \mathrm{~S}_{12}$ exhibit limited stability. ${ }^{9 \mathrm{~d},{ }^{9 f}}$ Despite some drawbacks, these results suggest that materials discovery of crystalline lithium sulfides, especially environmentally stable thiogermanates, is attractive for advancing $\mathrm{Li}^{+}$ion conductors for the next generation of all-solid-state batteries. Therefore, we propose that systematic changes in the composition of diamond-structured $\mathrm{Li}_{2}-\mathrm{II}-\mathrm{GeS}_{4}$ can provide access to new Li-based solid-state electrolytes, physicochemical property alterations, and structural variations.

Herein, we present the first systematic study of lithium ion conductivity in quaternary, diamondstructured thiogermanates, which constitute a new class of lithium ion conductors. Three structural modifications (Figure 1) can be controlled through $d$ block element selection in the $\mathrm{Li}_{2}$-II-GeS 4 family. These investigations led to the discovery of a new member of the wurtz-kesterite family, $\mathrm{Li}_{2} \mathrm{CoGeS}_{4}$. The synthesis, single crystal X-ray structure, and synchrotron X-ray powder diffraction coupled with Rietveld refinement of a bulk sample of $\mathrm{Li}_{2} \mathrm{CoGeS}_{4}$ are reported. Four diamond-like materials in three different structure types are considered as $\left[\mathrm{II}-\mathrm{GeS}_{4}\right]^{2-}$ anionic networks with varying net topologies that encompass $\mathrm{Li}^{+}$ions. As the cation arrangements are modified, lithium environments and diffusion capabilities in $\mathrm{Li}_{2}-\mathrm{II}-\mathrm{GeS}_{4}$ are altered. Lithium ion conductivity is reported for $\mathrm{Li}_{2}-\mathrm{II}-\mathrm{GeS}_{4}(\mathrm{II}=\mathrm{Mn}, \mathrm{Co}$, $\mathrm{Fe}, \mathrm{Cd}$ ) diamond-like materials, as assessed using impedance spectroscopy. 


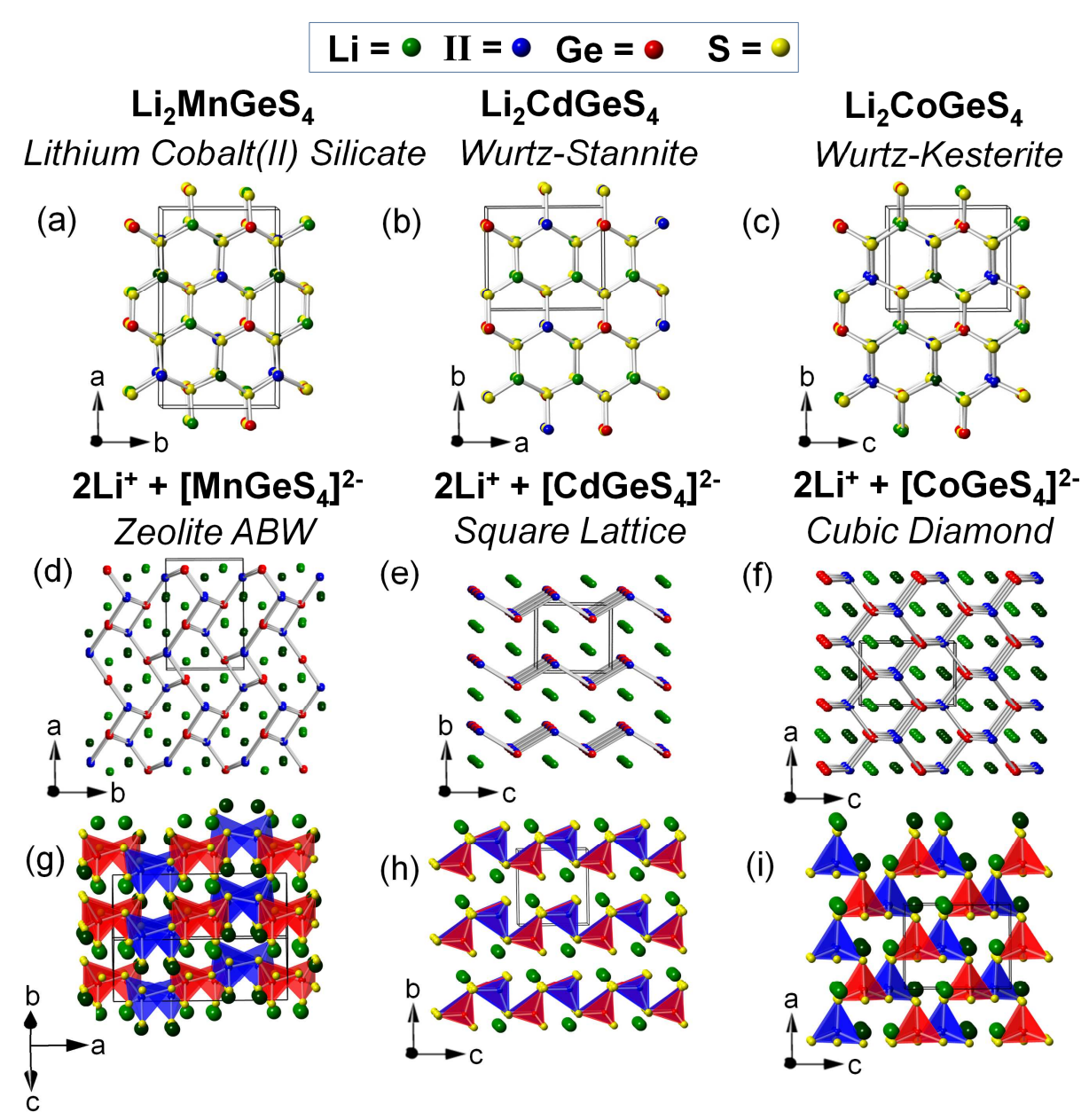

Figure 1. (a-c) Hexagonally derived structures for $\mathrm{I}_{2}-\mathrm{II}-\mathrm{IV}-\mathrm{VI}_{4}$ diamond-like materials (d-f) viewed as the corresponding anionic nets that house lithium ions. (g-i) The structures are oriented to emphasize potential lithium ion diffusion pathways. Sulfide ions are removed for clarity in d-i.

\subsection{EXPERIMENTAL}

2.1 Synthesis. $\mathrm{Li}_{2} \mathrm{CoGeS}_{4}$ was prepared by grinding $\mathrm{Li}_{2} \mathrm{~S}(1.2 \mathrm{mmol})$, $\mathrm{Co}(1 \mathrm{mmol}), \mathrm{Ge}(1 \mathrm{mmol})$, and $\mathrm{S}(3 \mathrm{mmol})$ using an agate mortar and pestle in an argon-filled glovebox, and then placing the mixture into a graphite crucible inside a $12 \mathrm{~mm}$ o.d. fused-silica tube. The tube was sealed under a pressure of approximately $10^{-3}$ mbar. The sample was heated at $650{ }^{\circ} \mathrm{C}$ for 144 hours, slowly cooled to $550{ }^{\circ} \mathrm{C}$ in $100 \mathrm{~h}$ and then allowed to cool to room temperature naturally. The tube was opened under ambient conditions. Excess $\mathrm{Li}_{2} \mathrm{~S}_{\mathrm{x}}$ was removed by washing the product with N,N-dimethylformamide, methanol, and hexane. A bright-green polycrystalline phase was observed under an optical microscope. 
Polycrystalline samples of dark red $\mathrm{Li}_{2} \mathrm{FeGeS}_{4},{ }^{13}$ pale yellow $\mathrm{Li}_{2} \mathrm{CdGeS}_{4}{ }^{5 \mathrm{~b}}$ and pale orange $\mathrm{Li}_{2} \mathrm{MnGeS}_{4}{ }^{14}$ were prepared in a similar manner, as previously reported by Brant et al.

2.2 Sample preparation. Samples were ground for $30 \mathrm{~min}$ for synchrotron X-ray powder diffraction (SXRPD). In preparation for impedance spectroscopy, the ground samples were pelletized using a Carver press. Pellets with $13 \mathrm{~mm}$ diameter and approximately $0.5-2 \mathrm{~mm}$ thickness were pressed under $15,000 \mathrm{psi}$. The pellets were covered with a circular mask, $9.9 \mathrm{~mm}$ in diameter, for Au sputtering using a Denton Vacuum Desk II Sputter Coater.

2.3 Single crystal X-ray diffraction. Single crystal X-ray diffraction data for $\mathrm{Li}_{2} \mathrm{CoGeS}_{4}$ were collected at ambient temperature using a Bruker SMART Apex 2 CCD single crystal X-ray diffractometer utilizing graphite monochromatized molybdenum $\mathrm{K}_{\alpha}$ radiation with a tube power of 50 $\mathrm{kV}$ and $30 \mathrm{~mA}$ for $30 \mathrm{sec}$ per frame. The data were integrated using $\mathrm{SAINT}^{15}$ and the absorption correction was applied using SADABS. ${ }^{16}$ XPREP was used for space group determination and to create files for SHELXTL. ${ }^{17}$ Based on systematic absences, two space groups were initially considered for $\mathrm{Li}_{2} \mathrm{CoGeS}_{4}, P n$ and $P 2 / n$. The space group $P n$ (No. 7) was selected because all diamond-like structures are noncentrosymmetric, since all tetrahedra align along one crystallographic direction.

The crystal structure of $\mathrm{Li}_{2} \mathrm{CoGeS}_{4}$ was solved and refined using the SHELXTL-PC ${ }^{17}$ software package. The $\mathrm{Li}_{2} \mathrm{CoGeS}_{4}$ structure consists of eight crystallographically unique atoms located on general positions: two $\mathrm{Li}$ sites, one Co site, one Ge site, and four $\mathrm{S}$ sites. The structure of $\mathrm{Li}_{2} \mathrm{CoGeS}_{4}$ was refined with $\mathrm{R}_{1}$ (all data) of $1.16 \%$. Lithium sites were refined isotropically, resulting in a non-positive definite atomic displacement parameter for the $\operatorname{Li}(2)$ site, while all other atoms were refined anisotropically. Since $\beta=90.000^{\circ}$, the structure solution and refinement was attempted in the orthorhombic space group $P m n 2_{1}$. However, this resulted in a chemically unreasonable model with a minimum achievable $\mathrm{R}_{1}$ (all data) value above $30 \%$. Further crystallographic details for the new 


\subsection{Synchrotron X-ray powder diffraction (SXRPD). Room temperature SXRPD data were collected} at the Advanced Photon Source, Argonne National Laboratory at the 11-BM line using a wavelength of $0.413733 \AA$. The 11-BM instrument uses X-ray optics with two platinum-striped mirrors and a doublecrystal $\mathrm{Si}(111)$ monochromator, where the second crystal has an adjustable sagittal bend. ${ }^{20}$ Ion chambers monitor incident flux. A vertical Huber 480 goniometer, equipped with a Heidenhain encoder, positions an analyzer system comprised of twelve perfect $\mathrm{Si}(111)$ analyzers and twelve Oxford-Danfysik $\mathrm{LaCl}_{3}$ scintillators, with a spacing of $2^{\circ} 2 \theta .^{21}$ The analyzer orientation can be adjusted individually on two axes. A three-axis translation stage holds the sample mounting and allows it to be spun, typically at 5400 RPM $(90 \mathrm{~Hz})$. A Mitsubishi robotic arm is used to mount and dismount samples on the diffractometer.

The diffractometer is controlled via EPICS. ${ }^{22}$ Data are collected while continually scanning the diffractometer $2 \theta$ arm. A mixture of NIST standard reference materials, $\mathrm{Si}$ (SRM 640c) and $\mathrm{Al}_{2} \mathrm{O}_{3}(\mathrm{SRM}$ 676), is used to calibrate the instrument, where the Si lattice constant determines the wavelength for each detector. Corrections are applied for detector sensitivity, $2 \theta$ offset, small differences in wavelength between detectors, and the source intensity, as noted by the ion chamber before merging the data into a single set of intensities evenly spaced in $2 \theta$.

Rietveld refinements were performed using GSAS with the EXPGUI interface. ${ }^{23}$ The structure of $\mathrm{Li}_{2} \mathrm{CoGeS}_{4}$ obtained by single crystal X-ray diffraction was used as the starting model. The background was fitted using a shifted Chebyschev polynomial. Peak shapes were modeled using Lorentzian terms, the Lorentzian isotropic crystallite size broadening (LX) and Lorentizian isotropic strain broadening 
(LY), within the type-3 profile function. Lattice parameters, atomic coordinates, and isotropic displacement parameters were refined. Resulting unit cell parameters, atomic coordinates, bond lengths and bond angles are provided in Tables S4-S7.

\subsection{Scanning electron microscopy and energy dispersive spectroscopy (SEM/EDS). Energy} dispersive spectroscopy (EDS) was performed on a Hitachi S-3400N scanning electron microscope equipped with a Bruker Quantax model 400 energy dispersive spectrometer using an XFlash ${ }^{\circledR} 5010$ EDS detector with a $129 \mathrm{eV}$ resolution. The $\mathrm{Li}_{2} \mathrm{CoGeS}_{4}$ crystals were mounted on double-sided carbon tape that was adhered to an aluminum specimen holder. EDS data were collected at a working distance of $10 \mathrm{~mm}$ and an accelerating voltage of $15 \mathrm{kV}$ for 5 min live time.

EDS confirmed the presence of $\mathrm{Co}, \mathrm{Ge}$, and $\mathrm{S}$ in the crystals; Li cannot be detected using this method. EDS results indicated a stoichiometry of $\mathrm{Co}_{1.0} \mathrm{Ge}_{1.0} \mathrm{~S}_{3.9}$

2.6 Impedance spectroscopy. Data were collected on pressed pellets of $\mathrm{Li}_{2} \mathrm{CoGeS}_{4}, \mathrm{Li}_{2} \mathrm{FeGeS}$, $\mathrm{Li}_{2} \mathrm{MnGeS}_{4}$, and $\mathrm{Li}_{2} \mathrm{CdGeS}_{4}$ using a Novocontrol Technologies Concept 80 impedance spectrometer. To avoid surface oxidation, the pellets were placed into a specialized air-tight sample holder, under a nitrogen atmosphere, that is comprised of two electrodes with spring-loaded platinum mesh contacts. The gold that was sputtered onto the pressed sample pellets served as an ion-blocking electrode. Temperature-dependence data were collected in increments of $12.5^{\circ} \mathrm{C}$ at temperatures ranging from 12.5 to $100^{\circ} \mathrm{C}$, since $100{ }^{\circ} \mathrm{C}$ is near the upper limit for which sample oxidation is precluded by the sample holder. The data were collected at frequencies ranging from $100 \mathrm{~Hz}$ to $3 \mathrm{MHz}$ with an applied root-mean-square $\mathrm{AC}$ voltage of $1 \mathrm{~V}$. The temperature was allowed to stabilize within $0.5{ }^{\circ} \mathrm{C}$ of each set temperature for three minutes prior to data collection. Complex impedance arcs were analyzed using Novocontrol WinFIT 3.2 software (Novocontrol Technologies GmbH \& Co. KG). Data sets were 
collected from low temperature to high temperature, and subsequent data re-collection at room temperature and then high temperature indicated reproducibility.

\subsection{RESULTS AND DISCUSSION}

3.1 Structure descriptions. $\mathrm{I}_{2}-\mathrm{II}-\mathrm{IV}-\mathrm{VI}_{4}$ diamond-like materials are structurally derived from cubic diamond or the more rare hexagonal diamond, lonsdaleite. Varying the elements used in the construction of diamond-structured $\mathrm{I}_{2}-\mathrm{II}-\mathrm{IV}-\mathrm{VI}_{4}$ compounds yields dissimilar cation ordering arrangements that, in turn, dictate different lithium ion diffusion pathways. Three types of cation ordering arrangements have been observed in quaternary diamond-like structures derived from lonsdaleite, giving rise to crystal structures in $P n a 2_{1}, P m n 2_{1}$, and $P n$ space groups, as shown in Figure 1. Here, these structure types have been controlled as a function of $d$ block element selection.

\subsection{1 $\mathrm{Li}_{2} \mathrm{CoGeS}_{4}$ and $\mathrm{Li}_{2} \mathrm{FeGeS}_{4}$ in the $P n$ space group.}

Employing $\mathrm{Co}$ as the divalent cation in the $\mathrm{Li}_{2}-\mathrm{II}-\mathrm{GeS}_{4}$ system provides access to the new $\mathrm{Li}_{2} \mathrm{CoGeS}_{4}$ that crystallizes with the wurtz-kesterite ${ }^{24}$ structure in the monoclinic space group $P n$. Diamond-like $\mathrm{Li}_{2} \mathrm{FeGeS}_{4}{ }^{13,} 25$ also crystallizes in this structure, as well as $\mathrm{Li}_{2} \mathrm{FeSnS}_{4},{ }^{13,}{ }^{25} \mathrm{Li}_{2} \mathrm{CoSnS}_{4},{ }^{14}$ and $\mathrm{Li}_{2} \mathrm{ZnSnS}_{4} \cdot{ }^{26}$

The structure of $\mathrm{Li}_{2} \mathrm{CoGeS}_{4}$ is comprised of sulfide anions in a hexagonal closest packed array, with lithium, cobalt, and germanium ions occupying half of the tetrahedral holes. The local electrostatic valence is satisfied in this structure, as well as the others reported here, as each sulfide anion is coordinated by one divalent cobalt, one tetravalent germanium and two monovalent lithium ions. Each cation coordinates to four sulfide anions. $\mathrm{Li}_{2} \mathrm{CoGeS}_{4}$ contains two crystallographically unique $\mathrm{Li}$ sites, with $\mathrm{Li}(1)-\mathrm{S}$ and $\mathrm{Li}(2)-\mathrm{S}$ bond lengths ranging from 2.42(2) to 2.50(2) $\AA$ and 2.39(2) to 2.45(2) $\mathrm{A}$, respectively. These bond lengths are comparable to those in found in other lithium-containing diamondlike materials, ${ }^{25}$ such as $\mathrm{Li}_{2} \mathrm{FeGeS}_{4}(\mathrm{Li}(1)-\mathrm{S} 2.38(7)-2.50(4) \AA),{ }^{13,}{ }^{25} \mathrm{Li}_{2} \mathrm{ZnSnS}_{4}(2.36(7)-2.52(2) \AA),{ }^{26}$ 
$\mathrm{Li}_{2} \mathrm{FeSnS}_{4}(2.37(4)-2.52(3) \AA),{ }^{13}, 25$ and $\mathrm{Li}_{2} \mathrm{CdGeS}_{4}(2.402(9)-2.446(6) \AA)^{5 a}$ Along the a-axis in the $\mathrm{Li}_{2} \mathrm{CoGeS}_{4}$, rows of alternating $\mathrm{Li}^{+}$and $\mathrm{S}^{2-}$ ions can be observed. As viewed down the c-axis, $\mathrm{Li}^{+}$ions alternate with either $\mathrm{Co}^{2+}$ or $\mathrm{Ge}^{4+}$ cations. Ion conduction pathways can be envisioned along the b-axis as depicted in Figure 1i.

While this structure type is similar to wurtz-stannite and lithium cobalt(II) silicate, reported for $\mathrm{Li}_{2} \mathrm{CdGeS}_{4}{ }^{5 \mathrm{a}, \mathrm{b}}$ and $\mathrm{Li}_{2} \mathrm{MnGeS}_{4}{ }^{14}$ respectively, the structural variations essentially arise as a function of monovalent and divalent cation placement (Figure 1). All three structure types contain a hexagonally packed array of sulfide anions with tetravalent germanium ions that reside in analogous tetrahedral holes, while monovalent lithium ions and divalent cations fill the remaining half of the tetrahedral holes. It is noteworthy that the $\beta$ angle in the monoclinic structure of $\mathrm{Li}_{2} \mathrm{CoGeS}_{4}$ is $90.000(0)^{\circ}$. Although the unit cell parameters are comparable to those found in orthorhombic structures (e.g., wurtz-stannite-type $\mathrm{Li}_{2} \mathrm{CdGeS}_{4}$ and $\left.\mathrm{Li}_{2} \mathrm{CdSnS}_{4}\right),{ }^{5 \mathrm{a}}$ this structure cannot be described by $m m m$ symmetry as evidenced by the unreasonable models with inappropriately high $\mathrm{R}$ values that were obtained when we attempted to use $P n a 2_{1}$ and $P m n 2_{1}$ space groups for the structure solution. The difference in symmetry of the monoclinic structure versus the orthorhombic structure is not a result of lattice distortions that might be expected to lower the symmetry, but rather a product of the cation ordering arrangement that is evident in the symmetry equivalent reflections. The monoclinic $P n$ structure, in which $|\mathrm{F}(h k l)|=|\mathrm{F}(h \bar{k} l)| \neq|\mathrm{F}(\bar{h} k l)| \neq$ $|\mathrm{F}(h k \bar{l})|$, can be distinguished (except in a special case in which the $x$ parameters of all atoms are $0,1 / 4$, 1/2, or 3/4) from the orthorhombic Pmn $2_{1}$ structure where $|\mathrm{F}(h k l)|=|\mathrm{F}(h \bar{k} l)|=|\mathrm{F}(\bar{h} k l)|=|\mathrm{F}(h k \bar{l})| .^{24 \mathrm{a}}$ Systematic absences are key in distinguishing these closely related structure-types. The wurtz-kesterite structure lacks additional systematic absences that would indicate the presence of an axial glide and/or a $2_{1}$ screw axis. In addition to the systematic absences in single crystal X-ray diffraction data, the wurtzkesterite structure of $\mathrm{Li}_{2} \mathrm{CoGeS}_{4}$ is supported by Rietveld refinement using synchrotron X-ray powder diffraction data. 
Table 1. Crystallographic data and experimental details for $\mathrm{Li}_{2} \mathrm{CoGeS}_{4}$.

\begin{tabular}{l|l}
\hline Formula & $\mathrm{Li}_{2} \mathrm{CoGeS}_{4}$ \\
\hline Size $(\mathrm{mm})$ & $0.06 \times 0.06 \times 0.05$ \\
Temperature $(\mathrm{K})$ & 298 \\
Space group & $\mathrm{Pn}$ \\
$\mathrm{a}(\AA)$ & $6.1933(2)$ \\
$\mathrm{b}(\AA)$ & $6.5211(2)$ \\
$\mathrm{c}(\AA)$ & $7.8360(2)$ \\
$\beta\left({ }^{\circ}\right)$ & $90.000(0)$ \\
Volume $\left(\AA^{3}\right), \mathrm{Z}$ & $316.47(2), 2$ \\
Density $(\mathrm{g}$ cm
\end{tabular}

The diamond-structured $\mathrm{Li}_{2} \mathrm{CoGeS}_{4}$ and $\mathrm{Li}_{2} \mathrm{FeGeS}_{4}$ can be viewed as anionic frameworks in which lithium ions reside. The anionic $\left[\mathrm{CoGeS}_{4}\right]^{2-}$ and $\left[\mathrm{FeGeS}_{4}\right]^{2-}$ nets are comprised of a single vertex, with a 
coordination sequence of $4,12,24,42,64,92,124,162,252$ and a vertex symbol of 6(2).6(2).6(2).6(2).6(2).6(2). Therefore, the wurtz-kesterite structure can be viewed as a threedimensional anionic framework, with the commonly encountered topology of cubic diamond, ${ }^{27}$ that encompasses lithium ions.

3.1.2 $\mathrm{Li}_{2} \mathrm{MnGeS}_{4}$ in the Pna2 ${ }_{1}$ space group. As previously reported, $\mathrm{Li}_{2} \mathrm{MnGeS}_{4}{ }^{14}$ adopts the lithium cobalt(II) silicate ${ }^{28}$ structure type that is derived from hexagonal diamond (see Figure 1). This structure type is relatively rare for quaternary diamond-like materials, and $\mathrm{Li}_{2} \mathrm{MnGeS}_{4}$ is one of only two chalcogenides with this structure, ${ }^{29}$ and the first in the lithium-based family. ${ }^{14}$ Although the Li-S distances are within range for iono-covalent bonding, ${ }^{29}$ the structure can be viewed as a threedimensional $\left[\mathrm{MnGeS}_{4}\right]^{2-}$ framework if Li-S bonds are neglected. The $\left[\mathrm{MnGeS}_{4}\right]^{2-}$ net is constructed with a 4-coordinate node that has a coordination sequence $4,10,21,36,54,78,106,136,173,214$ and is described by a vertex symbol 4.6.4.6.6.8(2) that corresponds to the topology of the zeolite ABW (ie: sra $\left.-\mathrm{SrAl}_{2}\right)^{30}$

Much research has focused on obtaining chalcogenide analogues of zeolites ${ }^{31}$ by replacing the $\mathrm{Si}^{4+}, \mathrm{Al}^{3+}$, and $\mathrm{O}^{2-}$ in zeolites with $\mathrm{Ge}^{4+}$ or $\mathrm{Sn}^{4+}, \mathrm{Ga}^{3+}$ or $\mathrm{In}^{3+}$, and $\mathrm{S}^{2-}$ or $\mathrm{Se}^{2-}$, as pioneered by Bedard, Flanigen and co-workers. $^{32}$ Such approaches have provided a means to tune properties, including bandgap, luminescence, pore size, surface area and stability. Notably, the primarily electrostatic host-guest interactions in these open-framework chalcogenides are much weaker than those in the oxide-based zeolites and give rise to unique host-guest-related applications. ${ }^{33}$ In the unique example of the zeolitelike $\left[\mathrm{MnGeS}_{4}\right]^{2-}, \mathrm{Mn}^{2+}, \mathrm{Ge}^{4+}$, and $\mathrm{S}^{2-}$ ions replace $\mathrm{Si}^{4+}, \mathrm{Al}^{3+}$, and $\mathrm{O}^{2-}$ in the traditional zeolite, while $\mathrm{Li}^{+}$ guests serve to balance the charge of the anionic framework.

Lithium ions can potentially diffuse along intersecting unidimensional channels within the zeolite-like anionic network. Lithium ions align along the a-, b-, and c-axes in the structure. Along the b-axis, $\operatorname{Li}(1)$ ions are staggered between germanium ions and $\operatorname{Li}(2)$ ions are staggered between manganese ions. Along the c-axis, all lithium ions are staggered between sulfide anions. However, along the a-axis, $\operatorname{Li}(1)$ 
ions align in an unobstructed pathway and lithium diffusion can be envisioned in that direction. Another pathway for lithium ion diffusion can be envisioned orthogonal to the (085) plane as shown in Figure $1 \mathrm{~g}$.

3.1.3 $\mathrm{Li}_{2} \mathrm{CdGeS}_{4}$ in the $P m n 2_{1}$ space group. As previously reported by Lekse et al. ${ }^{5 \mathrm{a}}$ using single crystal X-ray diffraction and confirmed by Brant et al. ${ }^{5 b}$ via Rietveld refinement of synchrotron X-ray powder diffraction, the structure of $\mathrm{Li}_{2} \mathrm{CdGeS}_{4}$ is also derived from hexagonal diamond, but it crystallizes in the orthorhombic space group $P m n 2_{1}$ with the wurtz-stannite structure. ${ }^{24 a}$, 34 The pattern of cation arrangement in the wurtz-stannite structure yields lithium ions that are housed by twodimensional anionic $\left[\mathrm{CdGeS}_{4}\right]^{2-}$ layers. The $\left[\mathrm{CdGeS}_{4}\right]^{2-}$ layer is comprised of a 4-connected vertex with a coordination sequence of $4,8,12,16,20,24,28,32,36,40^{19}$ that corresponds to the well-known square lattice (sql) network. ${ }^{30 \mathrm{~b}}$ Here, the two-dimensional sql net is constructed with alternating $\mathrm{Cd}^{2+}$ and $\mathrm{Ge}^{4+}$ nodes and the layers stack along the b-axis. Thus, lithium ions have the potential to diffuse through the ac-plane, as shown in Figure 1h.

3.2 Synchrotron X-ray powder diffraction (SXRPD). Laboratory-grade X-ray powder diffraction employing an average wavelength of $1.5418 \AA$ indicated that the $\mathrm{Li}_{2} \mathrm{CoGeS}_{4}$ sample was synthesized with high phase-purity. However, adequate modeling of the data using the Rietveld method was hindered since cobalt, with an absorption edge of $1.6083 \AA{ }^{35}$ imparts significant X-ray absorption effects when using $\mathrm{Cu} \mathrm{K}_{\alpha}$ radiation. Thus, high-resolution SXRPD data with $\lambda=0.413733 \AA$ provided a valuable means for characterization (Figure 2). 


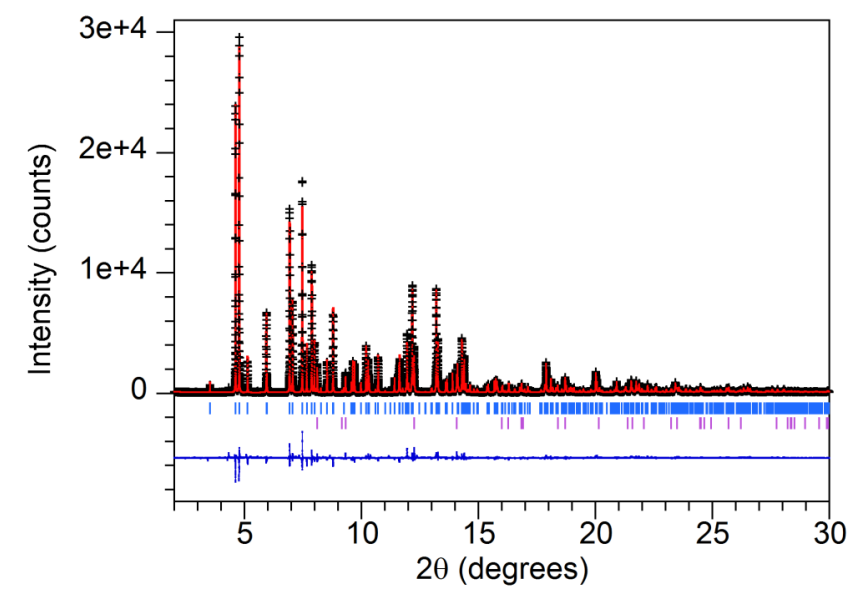

Figure 2. Rietveld refinement of $\mathrm{Li}_{2} \mathrm{CoGeS}_{4}$ using high-resolution synchrotron $\mathrm{X}$-ray powder diffraction data $(\lambda=0.413733)$, plotted with plus signs $(+)$ representing collected data overlapped by the pattern calculated from the model (line). Expected Bragg reflections for $\mathrm{Li}_{2} \mathrm{CoGeS}_{4}$ and $\mathrm{Co}_{3} \mathrm{~S}_{4}$ are displayed from top to bottom respectively, with tick marks $(\mid)$. The difference between the observed data and the calculated pattern is shown at the bottom of the plot.

Rietveld refinement using SXRPD data supports that $\mathrm{Li}_{2} \mathrm{CoGeS}_{4}$ crystallizes with the wurtz-kesterite structure, and evidence of neither the lithium cobalt(II) silicate structure nor the wurtz-stannite structure was observed in the polycrystalline powder sample. This Rietveld refinement indicates that the $\mathrm{Li}_{2} \mathrm{CoGeS}_{4}$ sample has been synthesized with phase-purity that is greater than $\sim 93 \%$. Several lowintensity reflections, which were not attributed to the diamond-like phase, were indexed to the mineral linnaeite, $\mathrm{Co}_{3} \mathrm{~S}_{4} \cdot{ }^{36}$ This minor phase was quantified as 5.2(2) wt $\%$. A few extra low-intensity peaks that could not be indexed were also observed. Of these peaks, the highest relative intensity is on the order of $\sim 1.4 \%$, whereas the highest intensity peak attributed to the linnaeite phase is $\sim 8 \%$ of the major peak indexed to the wurtz-kesterite structure. Agreement factors of $\chi^{2}=7.924, \mathrm{R}_{\mathrm{p}}=0.0979$, and $\mathrm{wR}_{\mathrm{p}}=$ 0.1334 were achieved. Various heating profiles and lithium polysulfide flux reactions were carried out to synthesize $\mathrm{Li}_{2} \mathrm{CoGeS}_{4}$; however the reaction conditions reported here yielded the highest phase purity. Rietveld refinements using SXRPD data for $\mathrm{Li}_{2} \mathrm{MnGeS}_{4},{ }^{14} \mathrm{Li}_{2} \mathrm{FeGeS}_{4}{ }^{13}$ and $\mathrm{Li}_{2} \mathrm{CdGeS}_{4}{ }^{5 \mathrm{~b}}$ were previously reported for samples that appeared phase-pure according to laboratory-grade X-ray powder 
diffraction. The $\mathrm{Li}_{2} \mathrm{MnGeS}_{4}$ sample has $>97 \mathrm{wt} \%$ phase purity according to SXRPD. ${ }^{14}$ Minor impurities of 1.74(3) wt $\% \mathrm{~S}_{8}{ }^{37}$ and 1.09(3) wt $\% \mathrm{Mn}_{2} \mathrm{GeS}_{4}{ }^{38}$ were observed. According to SXRPD, the $\mathrm{Li}_{2} \mathrm{FeGeS}_{4}$ product also contained a minor impurity phase that was not identified but indexed to a hexagonal space group. ${ }^{13} \mathrm{Li}_{2} \mathrm{CdGeS}_{4}$ exhibited phase-purity according to SXRPD data. ${ }^{5 b}$ Notably, all four of these chalcogenides are environmentally stable, which is evidenced by the diffraction patterns collected under ambient conditions that are reproducible over a period of a few weeks.

3.3 Lithium ion conductivity. The lithium ion conduction in $\mathrm{Li}_{2} \mathrm{CoGeS}_{4}, \mathrm{Li}_{2} \mathrm{FeGeS}_{4}, \mathrm{Li}_{2} \mathrm{MnGeS}_{4}$, and $\mathrm{Li}_{2} \mathrm{CdGeS}_{4}$ was evaluated using frequency-dependent complex impedance, $\hat{Z}(v)=Z^{\prime}(v)+i Z^{\prime}(v)$. The complex impedance plots, or Nyquist plots, exhibit characteristics of an ion conductor with contributions from the bulk material that is expected to constitute a semicircle in the low frequency regime, as well as intergranular contributions between the grains in the pellet that are observed as a semicircle in the low frequency data. Each semicircle is interpreted as the parallel combination of a resistor and a constant phase element (CPE). Complex impedance plots that show two arcs were fit using two circuits in series, as depicted in the inset of Figure 3. In some cases, evidence of two arcs is apparent at some temperatures while only the high frequency arc, or a portion thereof, is observed at others (e.g., $\mathrm{Li}_{2} \mathrm{FeGeS}_{4}$ in Figure 3). The data for $\mathrm{Li}_{2} \mathrm{FeGeS}_{4}$ at temperatures below $25{ }^{\circ} \mathrm{C}$ exhibit two arcs, while the data collected within the range of $37.5{ }^{\circ} \mathrm{C}$ to $100{ }^{\circ} \mathrm{C}$ reveal one arc. Similarly, the $\mathrm{Li}_{2} \mathrm{CdGeS}_{4}$ data contain two arcs, except for temperatures ranging from -12.5 to $12.5^{\circ} \mathrm{C}$ where only the high-frequency arc was observed. On the other hand, two arcs were evident in all data for $\mathrm{Li}_{2} \mathrm{CoGeS}_{4}$ (Figure 3). A single semicircle was apparent in all data for $\mathrm{Li}_{2} \mathrm{MnGeS}_{4}$. 
The resistance $(\mathrm{R})$ was assigned as the real component of impedance, $\mathrm{Z}^{\prime}(v)$, when the imaginary component of impedance, $i Z^{\prime \prime}(v)$, approaches zero at low frequency. The $\mathrm{Li}^{+}$ion conductivity values $(\sigma)$ were calculated using the resistance, pellet thickness and electrode area. The bulk conductivity values, corresponding to the higher-frequency arcs, are summarized in Table 2.

Figure 3. Complex impedance plots of (top) $\mathrm{Li}_{2} \mathrm{CoGeS}_{4}$ and (bottom) $\mathrm{Li}_{2} \mathrm{FeGeS}_{4}$. 
Table 2. Results from impedance spectroscopy

\begin{tabular}{|c|c|c|c|c|c|c|}
\hline Compound & Structure Type & $\begin{array}{l}\text { Anionic } \\
\text { Net }\end{array}$ & $\begin{array}{l}\text { Pellet Density } \\
(\%)\end{array}$ & $\sigma_{100^{\circ} \mathrm{C}}(\mathrm{S} / \mathrm{cm})$ & $\sigma_{25^{\circ} \mathrm{C}}(\mathrm{S} / \mathrm{cm})$ & $\mathbf{E}_{\mathrm{A}}(\mathrm{eV})$ \\
\hline $\mathrm{Li}_{2} \mathrm{FeGeS}_{4}$ & Wurtz-kesterite & $\begin{array}{l}\text { Cubic } \\
\text { diamond }\end{array}$ & 31.5 & $1.8(3) \times 10^{-4}$ & $3.8(4) \times 10^{-7}$ & $0.83(2)$ \\
\hline $\mathrm{Li}_{2} \mathrm{CoGeS}_{4}$ & Wurtz-kesterite & $\begin{array}{l}\text { Cubic } \\
\text { diamond }\end{array}$ & 36.6 & $2.47(3) \times 10^{-6}$ & $2.5(5) \times 10^{-9}$ & $0.87(1)$ \\
\hline $\mathrm{Li}_{2} \mathrm{MnGeS}_{4}$ & $\begin{array}{l}\text { Lithium cobalt(II) } \\
\text { silicate }\end{array}$ & $\begin{array}{l}\text { Zeolite } \\
\text { ABW }\end{array}$ & 58.8 & $2.14(3) \times 10^{-6}$ & $4.71(9) \times 10^{-9}$ & $0.83(2)$ \\
\hline $\mathrm{Li}_{2} \mathrm{CdGeS}_{4}$ & Wurtz-stannite & $\begin{array}{l}\text { Square } \\
\text { lattice }\end{array}$ & 44.5 & $3.31(4) \times 10^{-7}$ & $1.92(2) \times 10^{-9}$ & $0.74(2)$ \\
\hline
\end{tabular}

Pellet density $=($ actual pellet density/theoretical density $) \times 100$

The diamond-like compounds exhibit room temperature $\mathrm{Li}^{+}$ion conductivity on the order of $10^{-7}$ to $10^{-9}$ $\mathrm{S} / \mathrm{cm}$, which is significantly higher than that of ceramic pellets of the closely related ternary thiogermanate, $\mathrm{Li}_{2} \mathrm{GeS}_{3}$ as well as $\mathrm{Li}_{2} \mathrm{ZnGeS}_{4} \cdot{ }^{11}$ Comparable conductivity is only achieved at a temperature as high as $125{ }^{\circ} \mathrm{C}$ in pellets of $\mathrm{Li}_{2} \mathrm{GeS}_{3}\left(\sigma=9.7 \times 10^{-9} \mathrm{~S} / \mathrm{cm}\right)$, which crystallizes with an orthorhombic structure $(\mathrm{a}=5.90 \AA, \mathrm{b}=17.95 \AA, \mathrm{c}=6.81 \AA)$ and at $50{ }^{\circ} \mathrm{C}^{\mathrm{C}}$ in $\mathrm{Li}_{2} \mathrm{ZnGeS}_{4}\left(\sigma=9.7 \times 10^{-9}\right.$ S/cm), which has an orthorhombic $\beta-\mathrm{Li}_{3} \mathrm{PO}_{4}$ structure $\left(\mathrm{a}=7.83 \AA\right.$, $\mathrm{b}=6.53 \AA$ 的 $=6.21 \AA$ ). ${ }^{11}$ As shown in Table 2, the conductivity values reported correspond to pellets with compactness (i.e., percentage of theoretical density) less than $60 \%$. It should be noted that ion conduction is expected to significantly increase as the pellet density approaches the theoretical density, which may be achieved by heat treatment in inert atmosphere after pressing pellets or via hot pressing the pellets under dynamic vacuum. In the case of $\mathrm{Li}_{2} \mathrm{PO}_{2} \mathrm{~N}$, increasing the compactness from $55 \%$ to $78 \%$ in a pelletized sample 
resulted in a 16 fold rise in conductivity. ${ }^{39}$ Additionally, it is also important to point out that materials preparation greatly influences conductivity values. For example, an ion conductivity of $2.0 \times 10^{-7} \mathrm{~S} / \mathrm{cm}$ was recorded for a ceramic pellet of $\mathrm{Li}_{4} \mathrm{GeS}_{4}$ at $25{ }^{\circ} \mathrm{C} ;{ }^{11}$ however, a film of the compound was able to reach a value of $7.4 \times 10^{-4} \mathrm{~S} / \mathrm{cm}$ at $25{ }^{\circ} \mathrm{C} .{ }^{40}$ Even more impressive, a thin film of $\mathrm{Li}_{2} \mathrm{GeS}_{3}$ achieved an ion conductivity six orders of magnitude higher at $100{ }^{\circ} \mathrm{C}\left(2.9 \times 10^{-3} \mathrm{~S} / \mathrm{cm}\right)^{40}$ than a ceramic pellet. ${ }^{11}$ Thus, other forms of the diamond-like materials presented here hold promise.

Remarkably, the pellet of $\mathrm{Li}_{2} \mathrm{FeGeS}_{4}$ has the lowest percent compaction but exhibits the highest $\mathrm{Li}^{+}$ion conductivity, $\sigma_{100^{\circ} \mathrm{C}}=1.8(3) \times 10^{-4}$. Improved densification could yield conductivity values on par with leading solid-state electrolytes, such as LIPON films $\left(\sigma_{25^{\circ} \mathrm{C}}=2 \times 10^{-6}\right) \cdot{ }^{41}$

Overall, the cubic diamond-like $\left[\mathrm{CoGeS}_{4}\right]^{2-}$ and $\left[\mathrm{FeGeS}_{4}\right]^{2-}$, derived from the wurtz-kesterite structure, exhibit the highest $\mathrm{Li}^{+}$ion conductivity, followed by the $\mathrm{ABW}$ zeolite-like $\left[\mathrm{MnGeS}_{4}\right]^{2-}$ and square lattice-like $\left[\mathrm{CdGeS}_{4}\right]^{2-} . \mathrm{Li}_{2} \mathrm{FeGeS}_{4}$ is the most attractive as a solid-state electrolyte in regards to the conductivity, cost, and earth-abundance of iron and sulfur constituents. Redox properties are also an important consideration that has yet to be explored. Furthermore, optimization of the pellet densification processing for all of the quaternary thiogermanates, and especially for $\mathrm{Li}_{2} \mathrm{FeGeS}_{4}$, is warranted.

To assess the $\Delta \mathrm{E}_{\mathrm{A}}$ values for $\mathrm{Li}^{+}$ion conduction, the natural $\log$ of the bulk lithium ion conductivities obtained at each temperature for the diamond-like materials were plotted as a function of inverse temperature, as shown in Figure 4. The data are nearly linear, suggesting that the lithium ion diffusion in $\mathrm{Li}_{2} \mathrm{CoGeS}_{4}, \mathrm{Li}_{2} \mathrm{FeGeS}_{4}, \mathrm{Li}_{2} \mathrm{MnGeS}_{4}$, and $\mathrm{Li}_{2} \mathrm{CdGeS}_{4}$ follows the Arrhenius relationship, $\sigma_{\mathrm{dc}} \mathrm{T}=\mathrm{A} \exp (-$ $\Delta \mathrm{E}_{\mathrm{A}} / \mathrm{k}_{\mathrm{B}} \mathrm{T}$ ) within temperatures between $-12.5{ }^{\circ} \mathrm{C}$ and $100{ }^{\circ} \mathrm{C}$. The $\Delta \mathrm{E}_{\mathrm{A}}$ values for ion conduction are calculated using the slope of each linear fit, and are summarized in Table 2.

While the activation energies of the pelletized ceramics $\mathrm{Li}_{2} \mathrm{GeS}_{3}$ and $\mathrm{Li}_{4} \mathrm{GeS}_{4}$ have not been specified, ${ }^{11}$ the activation energies of the analogous thin films are $\sim 0.4 \mathrm{eV}^{40}$ The commercial LiPON films and the crystalline $\mathrm{Li}_{2} \mathrm{PO}_{2} \mathrm{~N}$ exhibit activation energies on the order of $\sim 0.6 \mathrm{eV}^{39,}{ }^{41}$ Although the activation energies for the four quaternary thiogermanates are higher, it is noteworthy that the $2 \mathrm{D}\left[\mathrm{CdGeS}_{4}\right]^{2-}$ net 
exhibits the lowest $\Delta \mathrm{E}_{\mathrm{A}}$ of $0.74 \mathrm{eV}$. This result can be rationalized since unobstructed lithium diffusion can be envisioned to occur throughout the ac-plane in the lithium cobalt(II) silicate structure type.

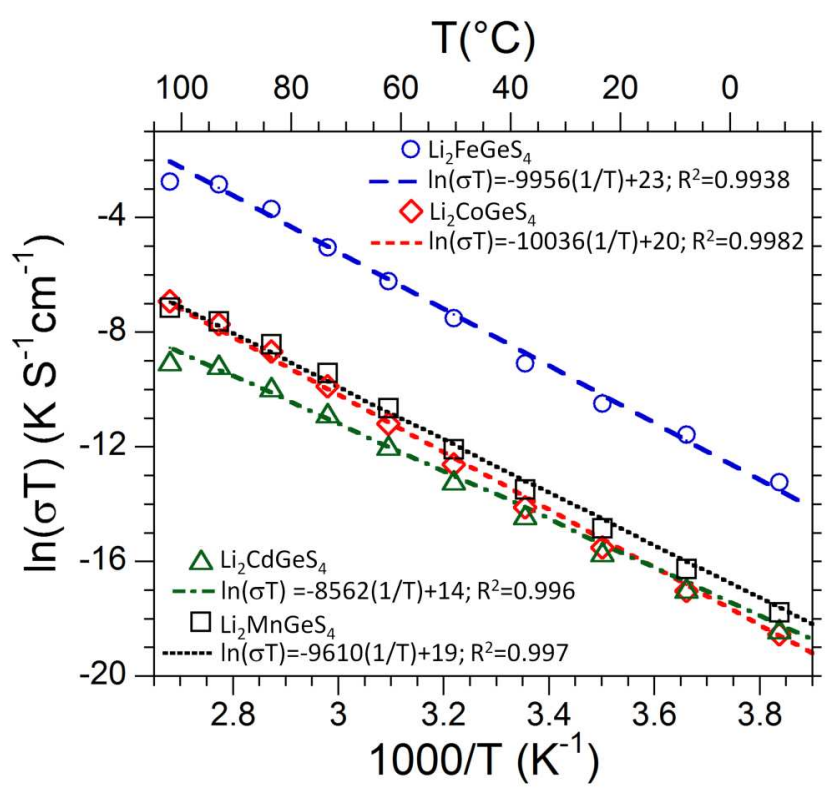

Figure 4. Arrhenius plot that represents the bulk conductivities extracted from complex impedance data collected from low to high temperatures for four diamond-like thiogermanates.

\subsection{CONCLUSIONS}

A new class of lithium ion conductors that exhibit environmental stability has been presented, in which different lithium diffusion pathways are accessed by varying the divalent metals (e.g., $\mathrm{Fe}^{2+}, \mathrm{Mn}^{2+}, \mathrm{Co}^{2+}$ ) employed in $\mathrm{I}_{2}$-II-IV-VI $\mathrm{I}_{4}$ diamond-like thiogermanates. The new diamond-structured $\mathrm{Li}_{2} \mathrm{CoGeS}_{4}$ crystallizes in the wurtz-kesterite structure that can be viewed as a $3 \mathrm{D}$ anionic $[\mathrm{CoGeS} 4]^{2-}$ net with cubic diamond topology that houses lithium ions. The analogous lithium-containing $\left[\mathrm{FeGeS}_{4}\right]^{2-}$ network exhibits the highest $\mathrm{Li}^{+}$ion conduction reported in this study, and is comprised of low-cost, earthabundant iron and sulfur.

In another report, an $\sim 20 \%$ increase in pellet density has led to a notable rise in ion conduction that is over two orders of magnitude. ${ }^{39}$ Since the pellet density of $\mathrm{Li}_{2} \mathrm{FeGeS}_{4}$ is only $\sim 30 \%$ of the theoretical density, such optimizations are expected to yield significant improvements. Accordingly, adding to the 
appeal of solid-state electrolytes in the family of $\mathrm{I}_{2}-\mathrm{II}-\mathrm{IV}-\mathrm{VI}_{4}$ diamond-like materials is the fact that members are readily prepared as films (e.g., $\mathrm{Cu}_{2} \mathrm{ZnSnS}_{4}$ ), ${ }^{3 \mathrm{~b}, 42}$ and ion conductivity has been shown to increase as much as six orders of magnitude in a thin film ternary thiogermanate compared to a ceramic pellet. $^{11,40}$

$\mathrm{Li}_{2} \mathrm{CdGeS}_{4}$, which consists of the $2 \mathrm{D}\left[\mathrm{CdGeS}_{4}\right]^{2-}$ with square lattice topology, exhibits the lowest activation energy for lithium ion conduction. The ion conductivity also has the potential to be improved significantly, as these studies were conducted on a pellet that has a density that is $\sim 45 \%$ of the theoretical density.

Perhaps even more intriguing, diamond-structured lithium ion conductors, $\mathrm{Li}_{2}-\mathrm{II}-\mathrm{IV}_{\mathrm{V}} \mathrm{VI}_{4}$, can be accessed via a reliable design strategy in which a wide variety of elements can be employed. Over forty compositions can be envisioned, while isovalent and aliovalent substitutions may have profound effects on lithium ion conduction and extend the new class to almost limitless combinations. The compositional flexibility in the family of $\mathrm{I}_{2}-\mathrm{II}-\mathrm{IV}-\mathrm{VI}_{4}$ diamond-structured materials provides a valuable platform to assess the effects of not only composition on structures within diamond derivatives, but also composition on properties. Acquiring a better understanding of the relationships between compositions, structures, and properties is key to developing future lithium ion conductors. 


\section{ACKNOWLEDGMENT}

This work was supported by the National Science Foundation (NSF) under Grants DMR-0645304

(CAREER Award) and DMR-1201729. Use of the Advanced Photon Source at Argonne National

Laboratory was supported by the U. S. Department of Energy, Office of Science, Office of Basic Energy

Sciences, under Contract No. DE-AC02-06CH11357. The work at Iowa State University by CB, DW, and SWM was supported by NSF grant no. DMR 1304977.

\section{REFERENCES}

1. (a) Venema, L., Nature 479 (2011), 309.(b) Szweda, R., Gallium arsenide, electronics materials and devices. A strategic study of markets, technologies and companies worldwide 1999-2004 (Third Edition). Elsevier Advanced Technology: Oxford, UK, 2005.

2. (a) Bhar, G. C.; Smith, R. C., Phys Status Solidi 13 (1972), 157.(b) Ruderman, W.; Maffetone, J.; Zelman, D.; Poirier, D., Mater. Res. Soc. Symp. Proc. 484 (1998), 519.(c) Chemla, D. S.; Kupecek, P. J.; Robertson, D. S.; Smith, R. C., Opt. Commun. 3 (1971), 29.

3. (a) Siebentritt, S.; Schorr, S., Prog. Photovolt. Res. Appl. 20 (2012), 512.(b) Ito, K.; Nakazawa, T., Jpn. J. Appl. Phys., Part 127 (1988), 2094.(c) Katagiri, H.; Saitoh, K.; Washio, T.; Shinohara, H.; Kurumadani, T.; Miyajima, S., Sol. Energy Mater. Sol. Cells 64 (2001), 141.

4. $\quad$ Liu, M.-L.; Chen, I.-W.; Huang, F.-Q.; Chen, L.-D., Adv. Mater. 21 (2009), 3808.

5. (a) Lekse, J. W.; Moreau, M. A.; McNerny, K. L.; Yeon, J.; Halasyamani, P. S.; Aitken, J. A., Inorg. Chem. (2009), 7516.(b) Brant, J. A.; Clark, D. J.; Kim, Y. S.; Jang, J. I.; Zhang, J.-H.; Aitken, J. A., Chem. Mater. (2014), 3045.(c) Jang, J. I.; Clark, D. J.; Brant, J. A.; AItken, J. A.; Kim, Y. S., Opt. Lett. 39 (2014), 4579.(d) Rosmus, K. A.; Brant, J. A.; Wisneski, S. D.; Clark, D. J.; Kim, Y. S.; Jang, J. I.; Brunetta, C. D.; Zhang, J.-H.; Srnec, M. N.; Aitken, J. A., Inorg. Chem. 53 (2014), 7809.(e) Aitken, J. A.; Brant, J. A.; Clark, D. J.; Kim, Y. S.; Jang, J. I., Impact of bandgap on infrared optical nonlinearity in novel quaternary chalcogenides: $\mathrm{Cu}_{2} \mathrm{CdSnS}_{4}$, a/b$\mathrm{Cu}_{2} \mathrm{ZnSiS}_{4}$ and $\mathrm{Li}_{2} \mathrm{CdSnS}_{4}$. In Nonlinear Optics: Fundamentals, Applications and Technological Advances, Wilkins, F., Ed. NOVA Scientific Publishers: New York, 2014.

6. Peled, E., J. Electrochem. Soc. 126 (1979), 2047.

7. (a) Harada, Y.; Hirakoso, Y.; Kawai, H.; Kuwano, J., J. Solid State Ionics 121 (1999), 245.(b) Inaguma, Y.; Liquan, C.; Itoh, M.; Nakamura, T., Solid State Commun. 86 (1993), 689.(c) Bohnke, O., Solid State Ion. 179 (2008), 9.

8. (a) Pradel, A.; Ribes, M., Mater. Chem. Phys. 23 (1989), 121.(b) Takada, K., Acta Mater. 61 (2013), 759.

9. (a) Seo, I.; Kim, Y., Solid State Ionics 261 (2014), 106.(b) Ito, S.; Nakakita, M.; Aihara, Y.; Uehara, T.; Machida, N., J. Power Sources 271 (2014), 342.(c) Kanno, R.; Murayama, M., J. Electrochem. Soc. 148 (2001), A742.(d) Kamaya, N.; Homma, K.; Yamakawa, Y.; Hirayama, M.; Kanno, R.; Yonemura, M.; Kamiyama, T.; Kato, Y.; Hama, S.; Kawamoto, K.; Mitsui, A., Nat. Mater. 10 (2011), 682.(e) Kuhn, A.; Duppel, V.; Lotsch, B. V., Energy Environ. Sci. 6 (2013), 3548.(f) Kuhn, A.; Gerbig, O.; Zhu, C., ;; Falkenberg, F.; Maier, J.; Lotsch, B. V., Phys. Chem. Chem. Phys. 16 (2014), 14669.(g) Bron, P.; Johansson, S.; Zick, K.; auf der Günne, J. S.; Dehnen, S.; Roling, B., J. Am. Chem. Soc. 135 (2013), 15694.(h) Kuhn, A.; Gerbig, O.; Zhu, C., ;; Falkenberg, F.; Maier, J.; Lotsch, B. V., Arxiv preprint, arXiv: 1402.4586 (2014).

10. Murayama, M.; Kanno, R.; Irie, M.; Ito, S.; Hata, T.; Sonoyama, N.; Kawamoto, Y., J. Solid State Chem. 168 (2002), 140. 
11. Kanno, R.; Hata, T.; Kawamoto, Y.; Irie, M., Solid State Ionics 130 (2000), 97.

12. (a) Kaib, T.; Haddadpour, S.; Kapitein, M.; Bron, P.; Schroder, C.; Eckert, H.; Roling, B.; Dehnen, S., Chem. Mater. 24 (2012), 2211.(b) Brant, J. A.; Massi, D. M.; Holzwarth, N. A. W.; MacNeil, J. H.; Douvalis, A. P.; Bakas, T.; Martin, S. W.; Gross, M. D.; Aitken, J. A., Chem. Mater. (2014), submitted.(c) Sahu, G.; Lin, Z.; Li, J.; Liu, Z.; Dudney, N.; Liang, C., Energy Environ. Sci. 7 (2014), 1053.

13. Brant, J. A.; dela Cruz, C.; Yao, J.; Douvalis, A. P.; Bakas, T.; Sorescu, M.; Aitken, J. A., Inorg. Chem. 53 (2014), 12265.

14. Brant, J. A.; Clark, D. J.; Kim, S. Y.; Jang, J. I.; Aitken, J. A., Inorg. Chem. (2014), submitted.

15. Bruker SMART and SAINT, Madison, Wisconsin, USA, 1998.

16. Sheldrick, G. M. SADABS, 2002.

17. SHELXTX-PC release 6.14, Bruker AXS, Madison, WI: 2007.

18. Palmer, D. Crystal Maker, CrystalMaker Software Ltd: Oxfordshire, England, 2010.

19. Blatov, V. A.; Shevchenko, A. P.; Proserpio, D. M., Cryst. Growth Des. 14 (2014), 3576.

20. Wang, J.; Toby, B. H.; Lee, P. L.; Ribaud, L.; Antao, S.; Kurtz, C.; Ramanathan, M.; Von Dreele, R. B.; Beno, M. A., Review of Scientific Instruments 79 (2008), 085105.

21. Lee, P. L.; Shu, D.; Ramanathan, M.; Preissner, C.; Wang, J.; Beno, M. A.; Von Dreele, R. B.; Lynn Ribaud; Kurtz, C.; Antao, S. M.; Jiao, X.; Toby, B. H., Journal of Synchrotron Radiation 15 (2008), 427.

22. Dalesio, L. R.; Hill, J. O.; Kraimer, M.; Lewis, S.; Murray, D.; Hunt, S.; Watson, W.; Clausen, M.; Dalesio, J., Nuclear Instruments \& Methods in Physics Research Section A-Accelerators Spectrometers Detectors and Associated Equipment 352 (1994), 179.

23. (a) Larson, A. C.; Von Dreele, R. B., Los Alamos National Laboratory Report LAUR (1994), 86.(b) Toby, B. H., J. Appl. Crystallogr. 34 (2001), 210.

24. (a) Parthé, E.; Yvon, K.; Deitch, R. H., Acta Crystallogr. 25 (1969), 1164.(b) Ilyukhin, V. V.; Nikitin, A. V.; Belov, N. V., Soviet Phys. Doklady 11 (1966), 1035.

25. Brunetta, C. D.; Brant, J. A.; Rosmus, K. A.; Henline, K. M.; Karey, E.; MacNeil, J. H.; Aitken, J. A., J. Alloys Compd 574 (2013), 495.

26. Lekse, J. W.; Leverett, B. M.; Lake, C. H.; Aitken, J. A., J. Solid State Chem. 181 (2008), 3217.

27. Delgado Friedrichs, O.; O'Keeffe, M.; Yaghi, O. M., Acta Cryst. A 59 (2003), 22.

28. Yamaguchi, H.; Akatsuka, K.; Setoguchi, M.; Takaki, Y., Acta Cryst. B B35 (1979), 2680.

29. Brunetta, C. D.; Minsterman, W. C.; Lake, C. H.; Aitken, J. A., J. Solid State Chem. 187 (2012), 177.

30. (a) Blatov, V. A.; Carlucci, L.; Ciani, G.; Proserpio, D. M., CrystEngComm 6 (2004), 377.(b) O'Keeffe, M.; Peskov, M. A.; Pamsden, S. J.; Yaghi, O. M., Acc. Chem. Res. 41 (2008), 1782.

31. Brant, J. A.; Brunetta, C. D.; Aitken, J. A., 5.09 - Chalcogenides and Nonoxides. In Comprehensive Inorganic Chemistry II (Second Edition), Reedijk, J.; Poeppelmeier, K. R., Eds. Elsevier: Amsterdam, The Netherlands, 2013; Vol. 5: Porous Materials and Nanomaterials, pp 213.

32. (a) Bedard, R. L.; WIlson, S. T.; Vail, L. D.; Bennett, J. M.; Flanigen, E. M., Stud. Surf. Sci. Catal. 49 (1989), 375.(b) Scott, R. W. J.; MacLaughlin, M. J.; Ozin, G. A., Curr. Opin. Solid State Mater. Sci. 4 (1999), 113.(c) Zheng, N.; Bu, X.; Wang, B.; Feng, P., Science 298 (2002), 2366.(d) Cheetham, A. K.; Ferey, G.; Loiseau, T., Angew. Chem. Int. Ed. 38 (1999), 3268.(e) Bu, X.; Zheng, N.; Feng, P., Chem. Eur. J. 10 (2004), 3356.

33. Zheng, N.; Bu, X.; Feng, P., Nature 426 (2003), 428.

34. Nitsche, R.; Sargent, D. F.; Wild, P., J. Cryst. Growth 1 (1967), 52.

35. Merritt, E. A. X-ray Absorption Edges. http://skuld.bmsc.washington.edu/scatter/AS_periodic.html.

36. Lundqvist, D.; Westgren, A., Z. Anorg. Allg. Chem. 239 (1938), 85.

37. Abrahams, S. C., Acta Crystallogr. 8 (1955), 661.

38. Hardy, A.; Perez, G.; Serment, J., B Soc Chim FR (1965), 2638. 
39. Senevirathne, K.; Day, C. S.; Gross, M. D.; Lachgar, A.; Holzwarth, N. A. W., Solid State Ionics 233 (2013), 95.

40. Seo, I.; Martin, S. W., Acta Materialia 59 (2011), 1839.

41. Wang, B.; Kwak, B. S.; Sales, B. C.; Bates, J. B., J. Non-Cryst. Solids 183 (1995), 297.

42. (a) Suryawanshi, M. P., Mater. Technol. 28 (2013), 98.(b) Seol, J. S.; Lee, S. Y.; Lee, J. C.; Nam, H. D.; Kim, K. H., Sol. Energy Mater. Sol. Cells 75 (2003), 155.(c) Tanaka, T.; Nagatomo, T.; Kawasaki, D.; Nishio, M.; Guo, Q. X.; Wakahara, A.; Yoshida, A.; Ogawa, H., J. Phys. Chem. Solids 66 (2005), 1978. 


$$
\mathrm{Li}=\bullet \mathrm{II}=\bullet \mathrm{Ge}=\bullet \quad \mathrm{S}=0
$$

\section{$\mathrm{Li}_{2} \mathrm{MnGeS}_{4} \quad \mathrm{Li}_{2} \mathrm{CdGeS}_{4}$}

Lithium Cobalt(II) Silicate Wurtz-Stannite

(a)

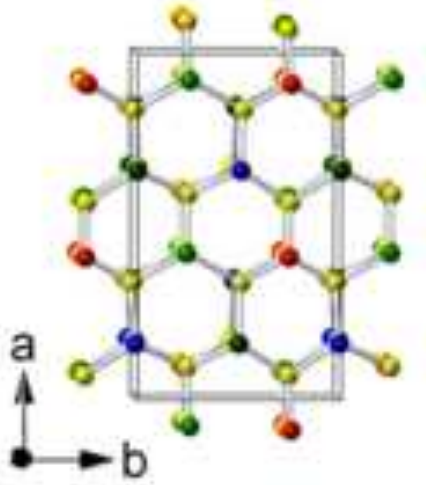

$2 \mathrm{Li}^{+}+\left[\mathrm{MnGeS}_{4}\right]^{2-}$

Zeolite ABW

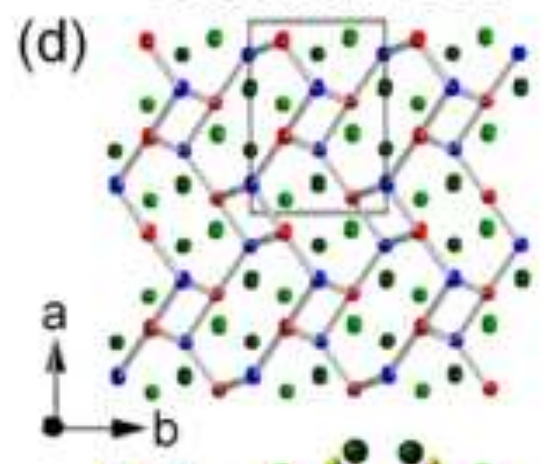

(g)

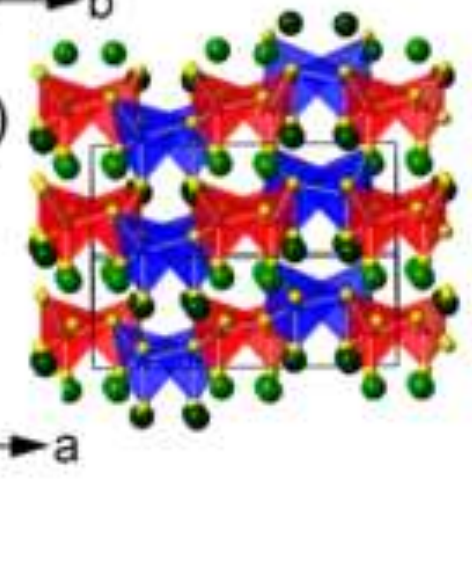

(b)

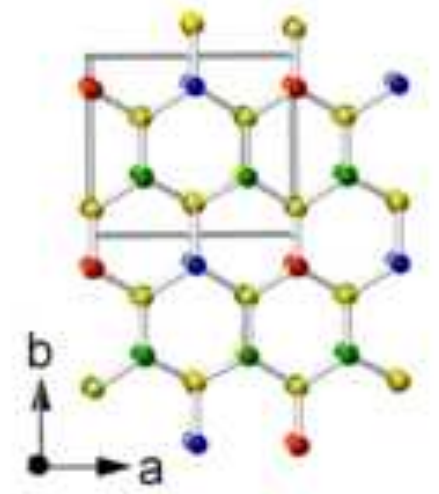

$2 \mathrm{Li}^{+}+\left[\mathrm{CdGeS}_{4}\right]^{2-}$ Square Lattice

(e)

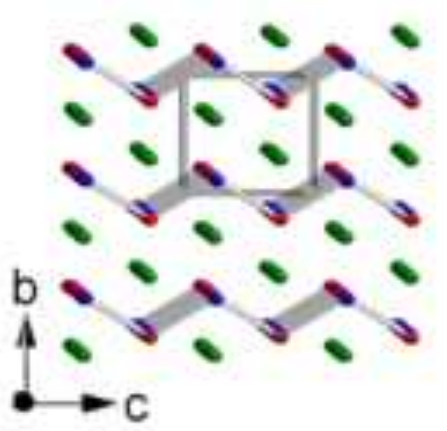

(h)
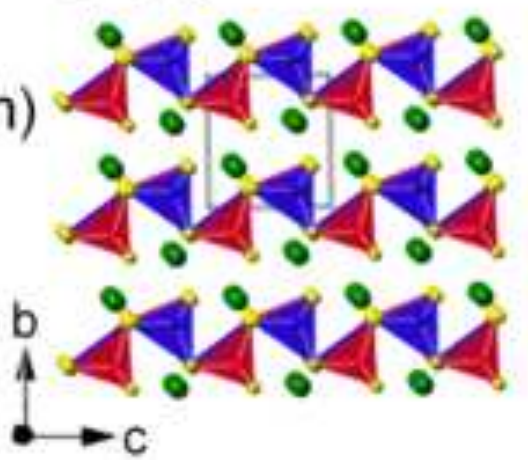

(c)

\section{$\mathrm{Li}_{2} \mathrm{CoGeS}_{4}$}

Wurtz-Kesterite

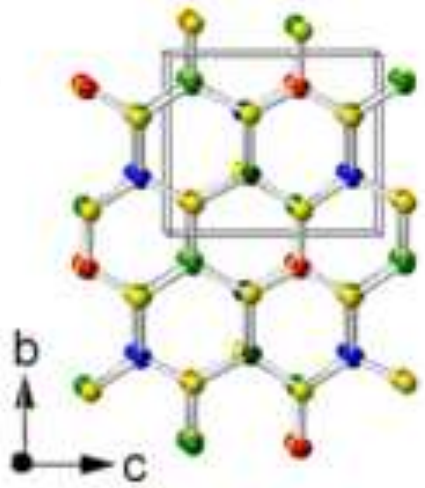

$2 \mathrm{Li}^{+}+\left[\mathrm{CoGeS}_{4}\right]^{2-}$

Cubic Diamond

(f)

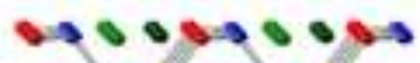

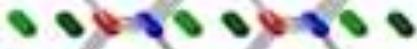

isposos os

- ibsosos os

as assos

a obso otsos

$4 \cos \theta 000$

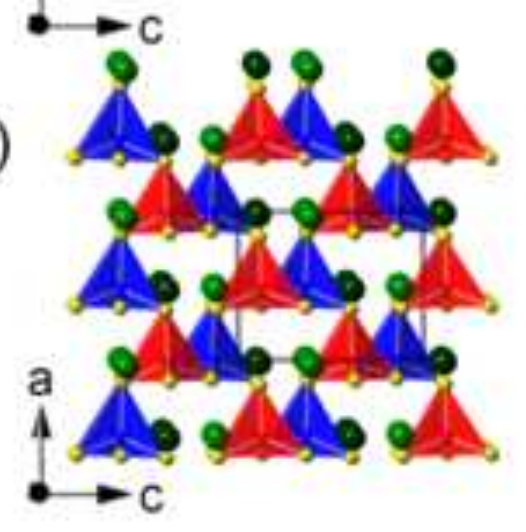

(i) 


\section{$\mathrm{Li}=\bullet \mathrm{II}=\bullet \mathrm{Ge}=\bullet \quad \mathrm{S}=0$}

\section{$\mathrm{Li}_{2} \mathrm{MnGeS}_{4}$}

Lithium Cobalt(II) Silicate

(a)

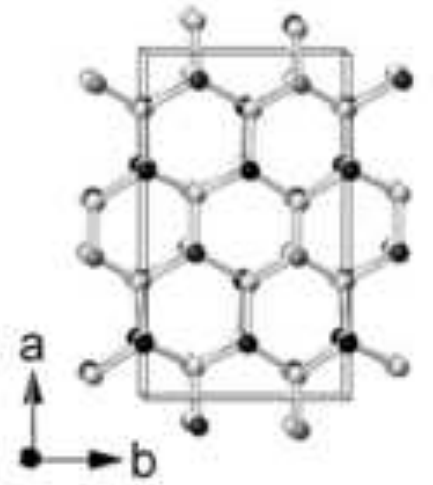

$2 \mathrm{Li}^{+}+\left[\mathrm{MnGeS}_{4}\right]^{2-}$

Zeolite ABW

(d)

$\because \%: \%$

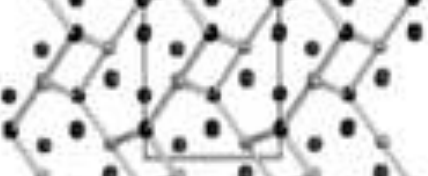

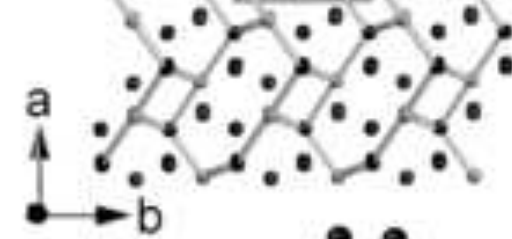

(g)
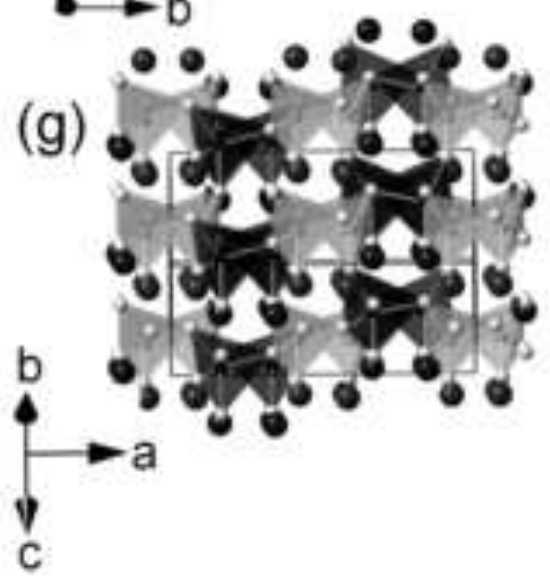

(b) $\mathrm{Li}_{2} \mathrm{CdGeS}_{4}$

Wurtz-Stannite

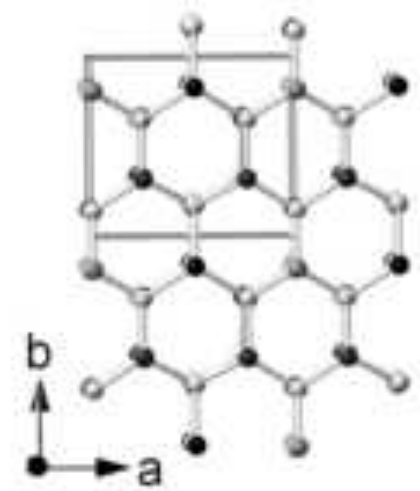

$2 \mathrm{Li}^{+}+\left[\mathrm{CdGeS}_{4}\right]^{2-}$ Square Lattice

(e)

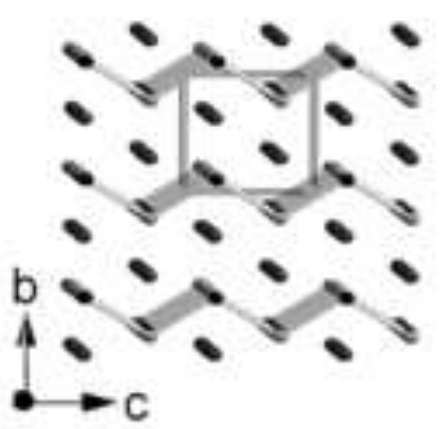

(h)
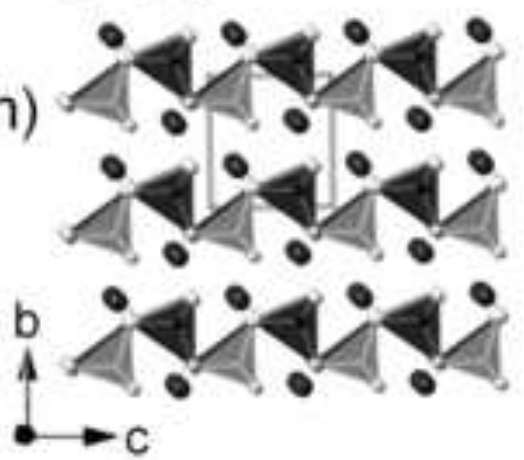

(c)

$\mathrm{Li}_{2} \mathrm{CoGeS}_{4}$

Wurtz-Kesterite

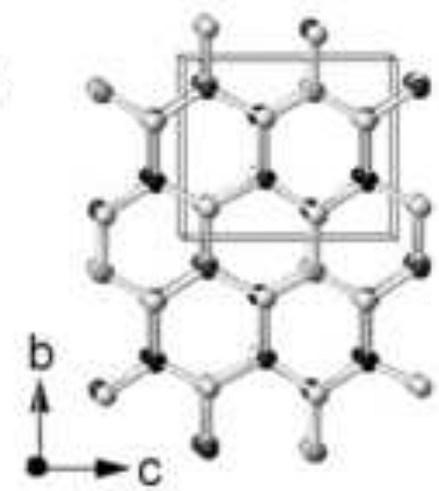

$2 \mathrm{Li}^{+}+\left[\mathrm{CoGeS}_{4}\right]^{2-}$

Cubic Diamond

(f)

os osis os

$-0 \cos 00$

os 0,5000

- gursosos

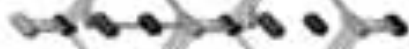

a $\theta-200,100$

$4 \cos \theta 000$

$\rightarrow c$

(i)
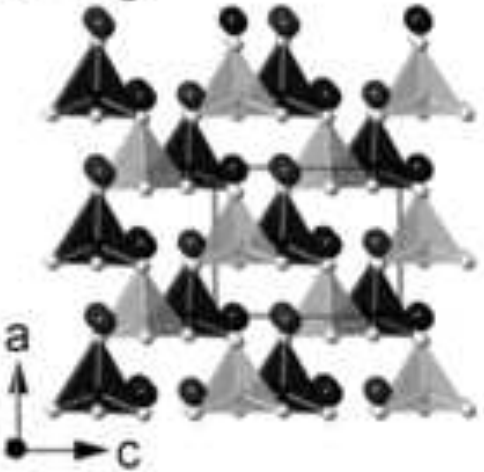


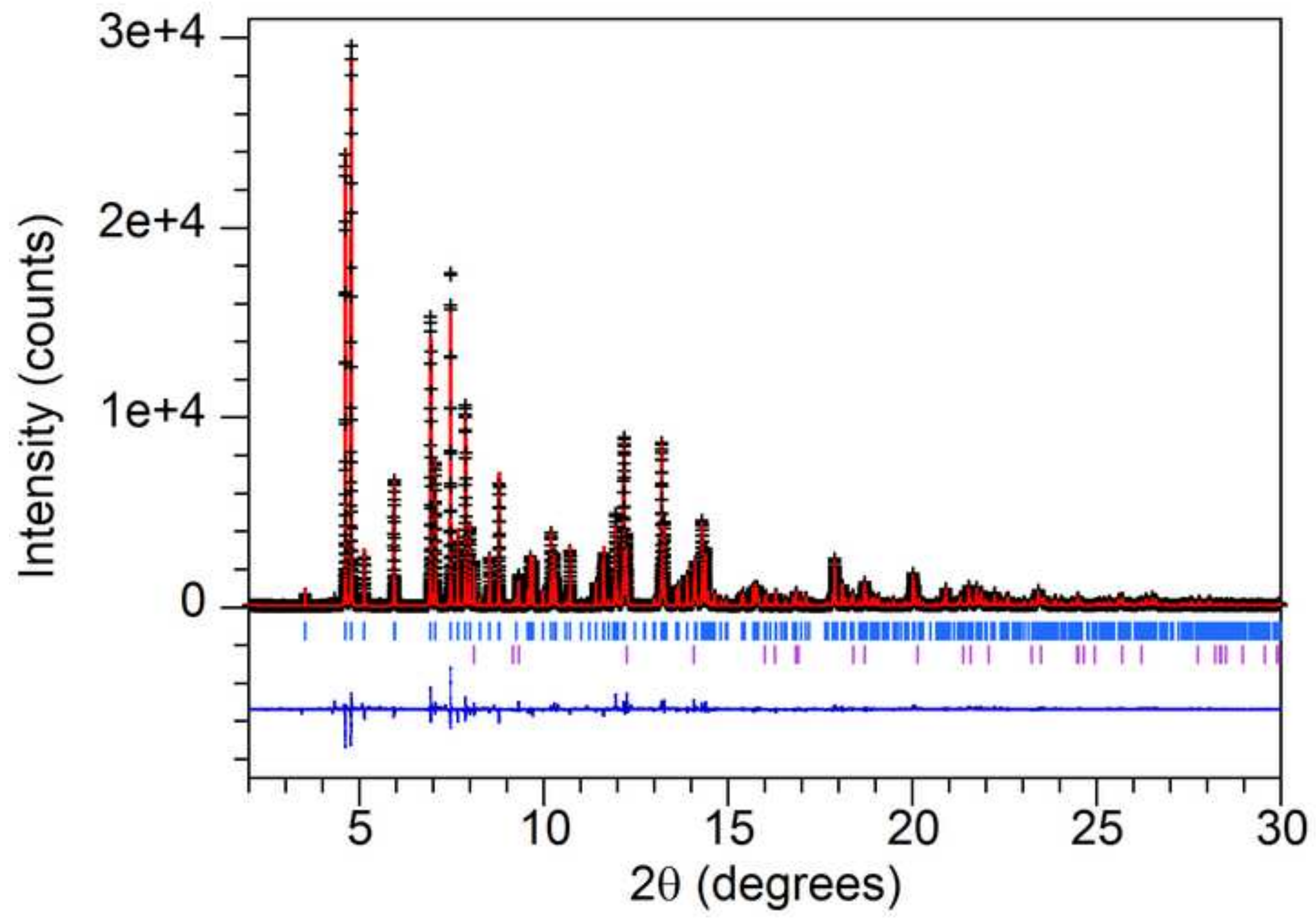




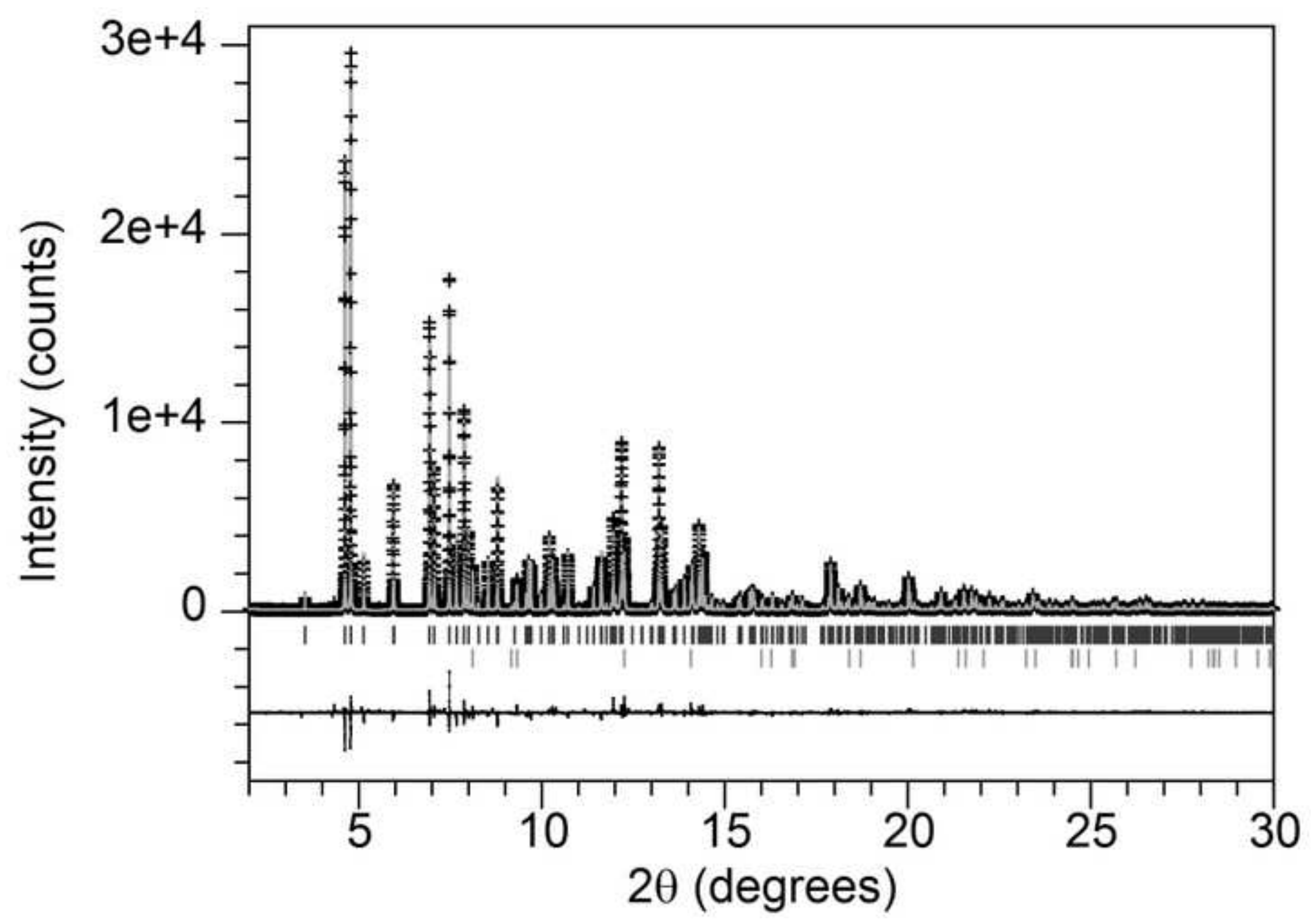



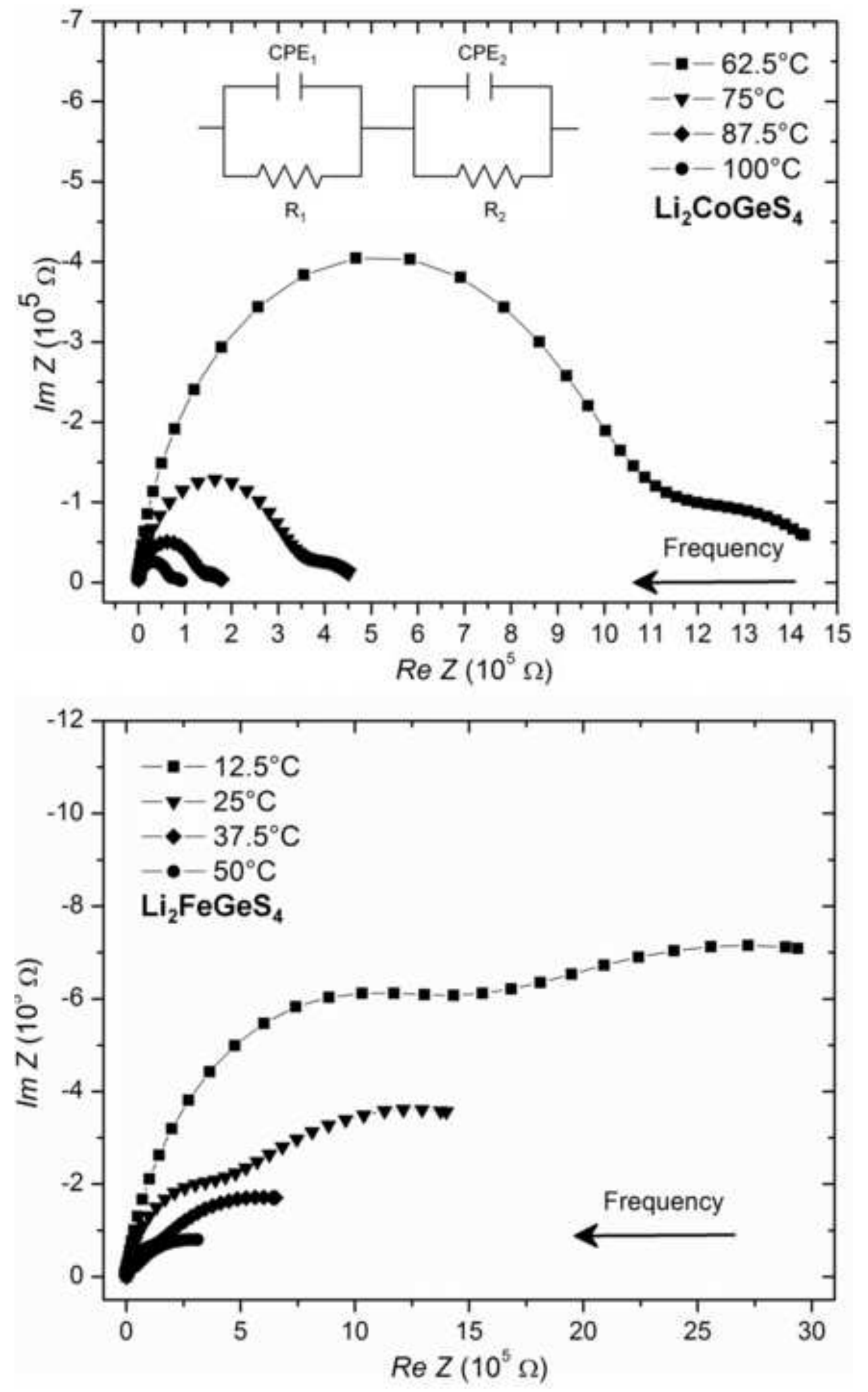

Figure 3 gray scale 


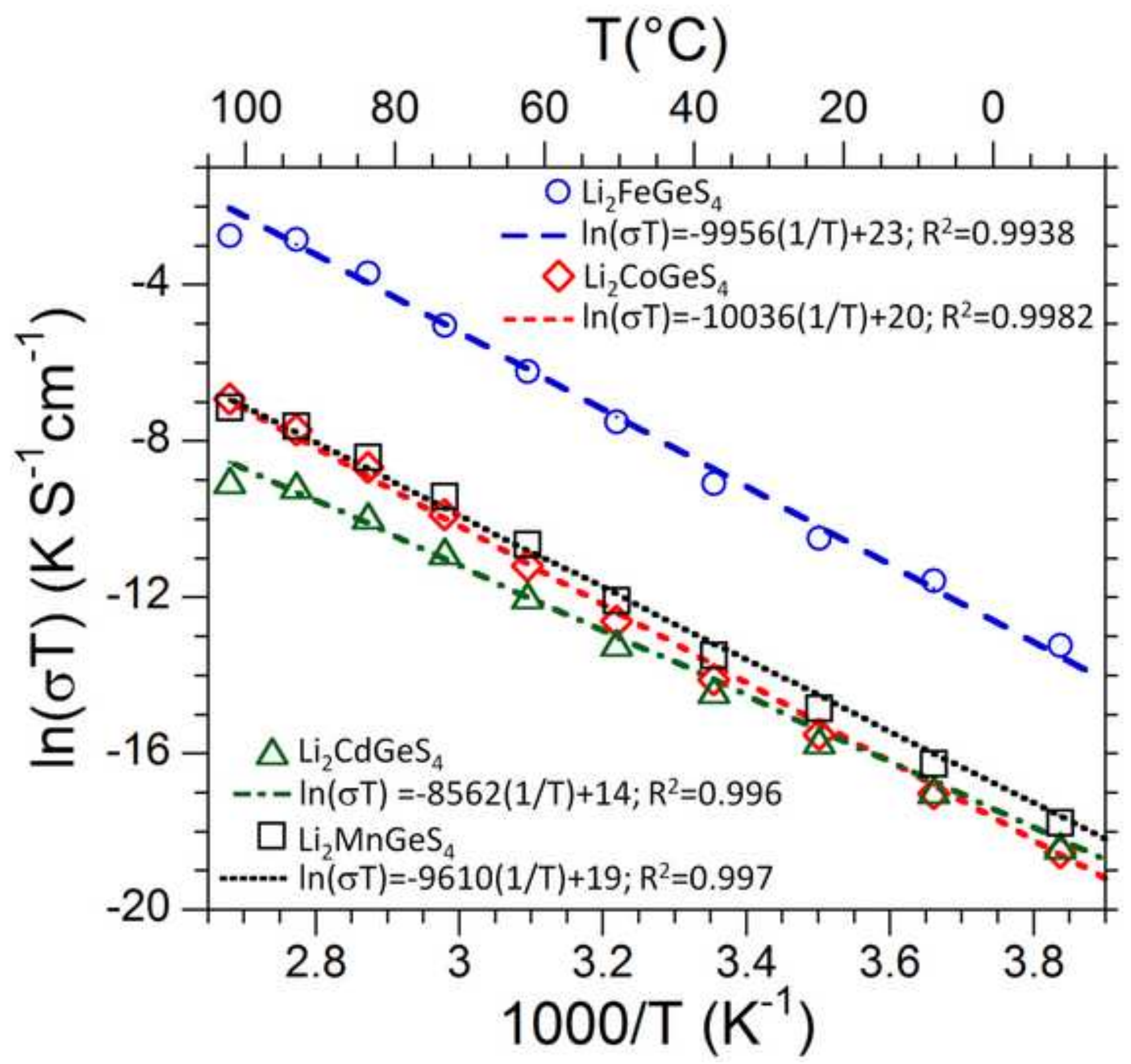

T $\left.{ }^{\circ} \mathrm{C}\right)$ 


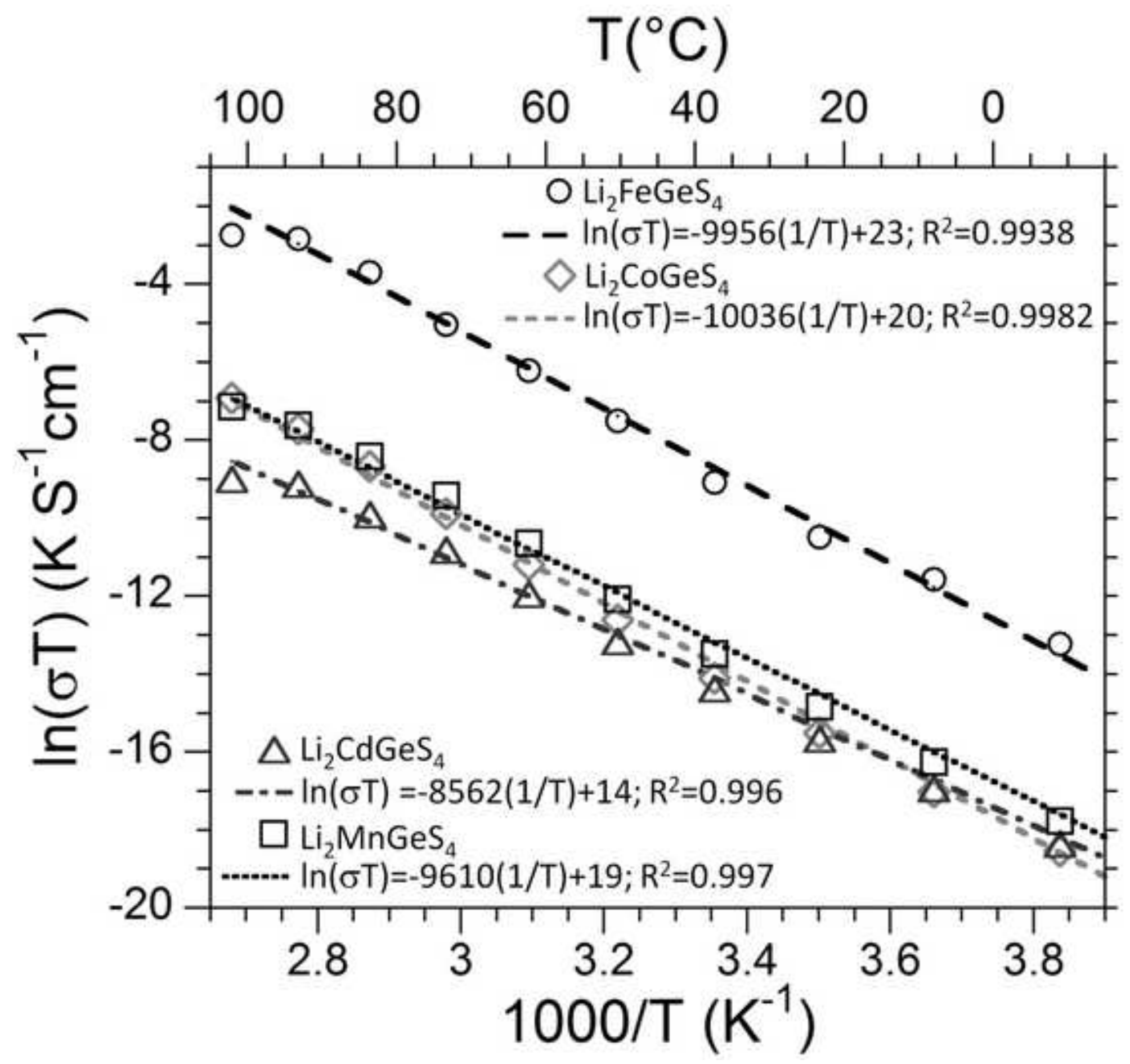

T $\left.{ }^{\circ} \mathrm{C}\right)$ 